\title{
In Memoriam HÉCTOR ARMANDO VARGAS GONZÁLEZ
}

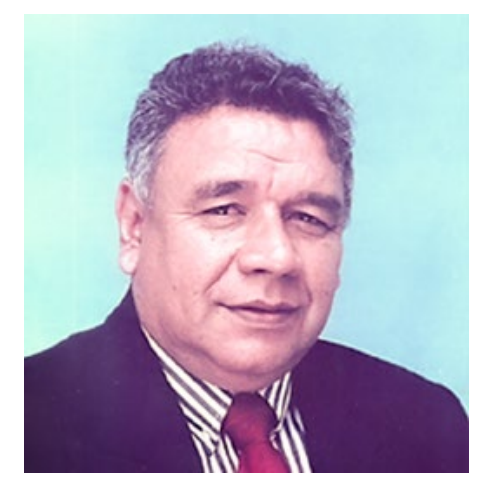

1943-2021

\section{JAMES MONTOYA LERMA';}

\author{
1Universidad de Valle, Cali, Colombia,james.montoya@correounivalle.edu.co
}

\begin{abstract}
Autor para correspondencia
James Montoya Lerma. Ciudad Universitaria Meléndez, Calle 13 No. 100-00, Cali, Colombia,james.montoya@correounivalle.edu.co

\section{Agradecimientos}

A los profesores F.A. Martínez, E.J. Peña, P. Chacón, I. Armbrecht. A los entomólogos L.A. Lastra y E. Torrado. A la familia Vargas. A cada uno por colaborar o motivar partes del escrito.

Revista Colombiana de Entomología ISSN (Print): 0120-0488

ISSN (On Line): $2665-4385$

https://revistacolombianaentomologia.univalle.edu.co

Open access

(c) (i) (2) (2) BY-NC-SA 4.0
\end{abstract}

Publishers: Sociedad Colombiana de Entomología SOCOLEN (Bogotá, D. C., Colombia) https://www.socolen.org.co

Universidad del Valle (Cali, Colombia)

https://www.univalle.edu.co

(C) 2021 Sociedad Colombiana de Entomología SOCOLEN y Universidad del Valle - Univalle
Quizá este sea el manuscrito más difícil, pero a la vez el de mayor gratitud que haya redactado. Aún sigo sin sobreponerme a la aciaga noticia que recibí el 6 de julio. A través de un lánguido mensaje, mi colega y amiga Luz Adriana Lastra me comparte la triste noticia: el infausto e inesperado deceso de nuestro bien querido Profesor Héctor A. Vargas. ¡Aquella noticia petrifica! Nos dejó estupefactos sin poder discernir si estamos en un espacio onírico o ante la cruel realidad. Pero esta pandemia ha cobrado su peaje y esta vez la víctima fue una persona que nos prodigó, más que conocimiento, una sabiduría revestida de amistad y de ingeniosa jocosidad. He de aclarar que toda intención que haga por retratar la imagen de este ser querido, con toda mi modesta intención, será imperfecta. Escapan a mí la posibilidad de plasmar miles de detalles de su vida y de los momentos inolvidables compartidos con él. Quizá los podría reunir si recurriera a los recuerdos de ese gran número de personas quienes tuvieron la fortuna de conocerle. Su mayor virtud fue siempre luchar por no ser ni virtuoso ni engreído. Fue persona sencilla, llana, colmada de carisma y gran intelecto. No obstante, a pesar de su sencillez, marcó una huella imborrable tanto como amigo y como maestro, con sus mensajes llenos de contenido humano. Armonizó la música con la academia, pasión que supo distinguir entre los principios éticos de su profesión y el espíritu jovial y lírico de su estilo personal. Ser muy singular quien me brindó cuando fui su estudiante muchos elementos indispensables para fungir como entomólogo y luego, sin recelos ni egoísmos me entregó todas las ayudas para las clases, amén de reglas y útiles consejos básicos para desempeñarme como docente.

En 1970, Héctor Armando Vargas González se graduó de ingeniero agrónomo en la Universidad del Tolima. Desde entonces, su pasión por la entomología fue evidente. En esa universidad hizo sus primeros pinitos en docencia como auxiliar de la cátedra de entomología. Dedicó más de 50 años de su vida a la enseñanza e investigación aplicada de la entomología económica y el control biológico de plagas. En estos campos fue un especialista en el reconocimiento y evaluación de problemas generados por artrópodos plagas en diferentes cultivos como en el análisis crítico de las tecnologías utilizadas para su manejo y control, dentro de un marco 
de producción y desarrollo sostenible. En estas áreas su influencia fue crucial para un gran grupo de discípulos que hoy ocupan importantes cargos a nivel nacional e internacional. En 1982 se vinculó como profesor de cátedra a la Universidad del Valle y luego en 1984 lo hizo como docente de tiempo completo al departamento de Biología. Eventualmente, laboró en la Universidad Nacional, sede Palmira. Todos los compañeros de mi cohorte en Univalle disfrutábamos de sus amenas y didácticas clases acompañadas de diapositivas y acetatos, todos muy prolijos y bien presentados. Muy responsable en la preparación de sus laboratorios y sobretodo de las salidas de campo. En ellas disfrutábamos del portento de su memoria al reconocer las especies de insectos en los diferentes agroecosistemas. Jamás olvidaremos sus exámenes prácticos de campo, ni los cientos de insectos de importancia económica que debíamos reconocer a especie y analizar. Como bonus, nos deleitaba con un repertorio de cuentos, anécdotas, chistes y proverbios con las cuales hacía muy amenas las actividades de campo. Un gran número de estudiantes desarrollaron trabajos de grado bajo su dirección, cubriendo estudios en insectos benéficos como Xylocopa spp., Bracon kirkpatricky, Polistes erythrocephalus y de plagas de cultivos de maracuyá, caña de azúcar, café, etc. Varios de esos trabajos fueron presentados, algunos premiados, en los congresos de la Sociedad Colombiana de
Entomología (SOCOLEN) y publicados en su revista científica. Se granjeó la amistad y reconocimiento de colegas de las universidades y centros de investigación científica (CIAT, ICA, CORPOICA (actual AGROSAVIA), CENICAFÉ, CENICAÑA, etc.). A su desempeño como docente e investigador universitario estuvieron vinculadas actividades de investigación y administración. Fue decano de Sede Regional del Pacífico de la Universidad del Valle, en Buenaventura, y jefe del Departamento de Biología de la misma universidad en Cali. Tuvo participación directa en el desarrollo de políticas académicas y administrativas para la proyección universitaria. Su interés por la ciencia entomológica no entró en diapausa con su jubilación. Por lo contrario, estuvo muy activo en calidad de docente invitado en los diplomados de paisajismo ofrecidos por la Facultad de Artes Integradas de Univalle, siempre fue receptivo a las invitaciones a ofrecer conferencias y, de forma independiente, investigaba en el desarrollo de endoterapia, práctica de aplicar sueros a los tallos de plantas para estimular su defensa ante plagas.

La inmortalidad no es distintiva de los dioses del Olimpo: el profe Vargas pervivirá entre nosotros gracias a su legado de múltiples enseñanzas que representan su perpetuidad entre nosotros. Espero recoger las expresiones de muchos colegas, estudiantes, amigos y familiares. ¡Nunca lo olvidaremos! Paz en su tumba.

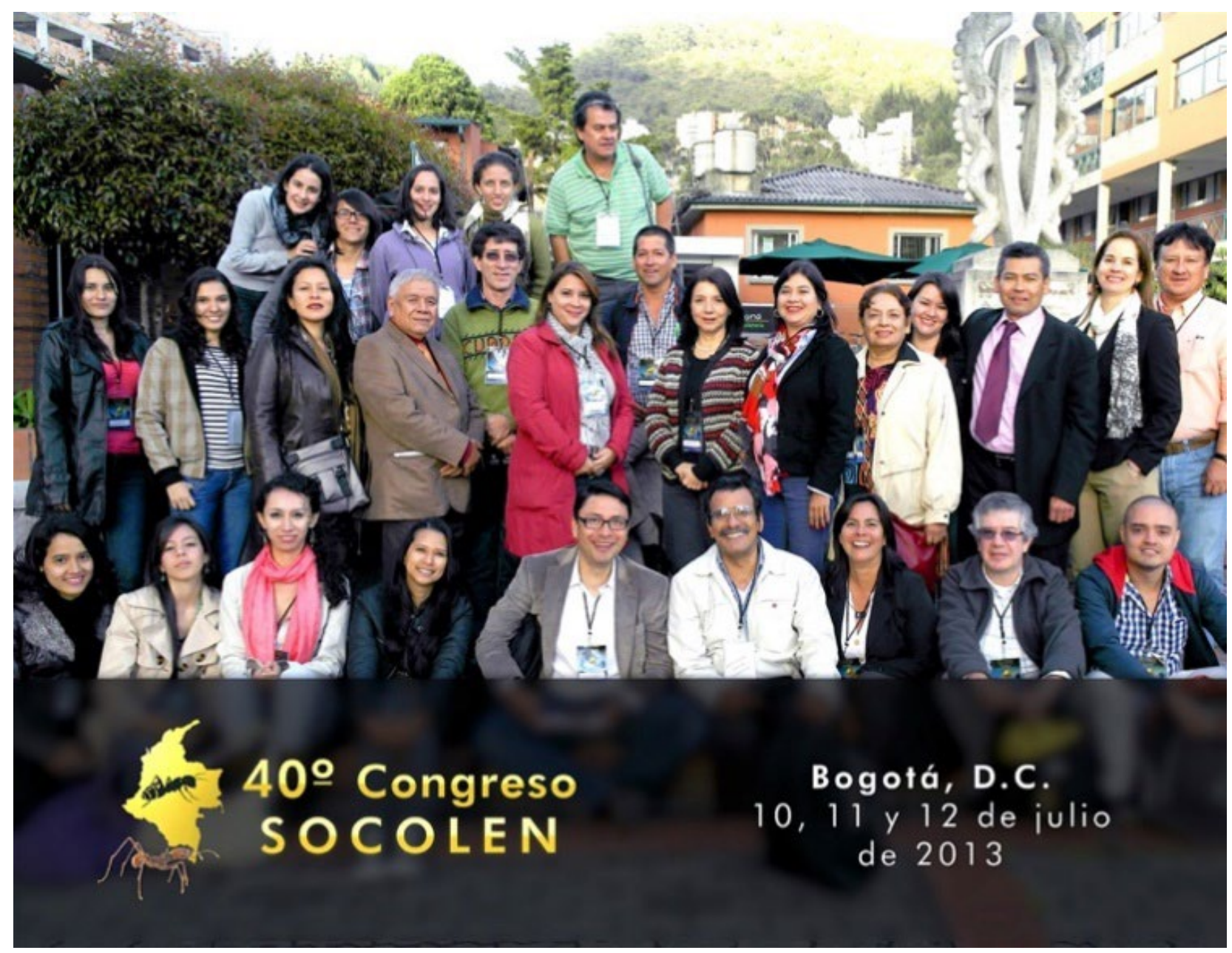

Figura 1. En la foto lograda en Bogotá durante el $40^{\circ}$ Congreso de Socolen, el profesor Vargas está en la fila del medio, de cuarto de derecha a izquierda. Le acompañamos colegas de Univalle, entomólogos egresados de varias promociones y estudiantes de entomología de Univalle. 